\title{
Potential value of electronic prescribing in health economic and outcomes research
}

This article was published in the following Dove Press journal:

Patient Related Outcome Measures

17 November 2010

Number of times this article has been viewed

\section{Catherine E Cooke' \\ Brian J Isetts ${ }^{2}$ \\ Thomas E Sullivan ${ }^{3}$ \\ Maren Fustgaard ${ }^{4}$ \\ Daniel A Belletti ${ }^{5}$}

'PosiHealth Inc., Ellicott City, MD, USA; ${ }^{2}$ Department of Pharmaceutical Care and Health Systems, University of Minnesota College of Pharmacy, Minneapolis, MN, USA; 'Women's Health Center, Danvers, MA, USA; ${ }^{4}$ Assistant Director for Regional Outcomes Research, ${ }^{5}$ Associate Director for Regional Outcomes Research, Novartis Pharmaceuticals Corporation, East Hanover, NJ, USA

Correspondence: Catherine E Cooke 5106 Bonnie Branch Road, Ellicott City, MD 21043, USA

$\mathrm{Tel} / \mathrm{Fax}+$ I 4I0 4805012

Email ccooke@posihealth.com
Abstract: Improving access and quality while reducing expenditures in the United States health system is expected to be a priority for many years. The use of health information technology (HIT), including electronic prescribing (eRx), is an important initiative in efforts aimed at improving safety and outcomes, increasing quality, and decreasing costs. Data from eRx has been used in studies that document reductions in medication errors, adverse drug events, and pharmacy order-processing time. Evaluating programs and initiatives intended to improve health care can be facilitated through the use of HIT and eRx. eRx data can be used to conduct research to answer questions about the outcomes of health care products, services, and new clinical initiatives with the goal of providing guidance for clinicians and policy makers. Given the recent explosive growth of eRx in the United States, the purpose of this manuscript is to assess the value and suggest enhanced uses and applications of eRx to facilitate the role of the practitioner in contributing to health economics and outcomes research.

Keywords: electronic prescribing, outcomes research, health information technology

\section{Background on electronic prescribing}

At its inception, electronic prescribing (eRx) was seen as a quality improvement tool and was defined as "the prescriber's ability to electronically send an accurate, errorfree, and understandable prescription directly to a pharmacy from the point-of-care". ${ }^{1}$ A more recent and comprehensive definition of $\mathrm{eRx}$ that we use throughout this article is the transmission, using electronic media, of prescription or prescription-related information between a prescriber, dispenser, pharmacy benefit manager, or health plan, either directly or through an intermediary, including an eRx network. ${ }^{2}$

A systematic review of the effects of computerization on doctors' performance from 1980 to 1997 found that eRx was the most commonly used feature of general practice computing and that computing systems could increase preventive health services, improve medication efficiency (generic utilization and cost), and decrease physician/staff time. ${ }^{3}$ Since 1997 (the end of the study period), the use of eRx has increased dramatically, particularly following the creations of the RxHub and the SureScripts networks, which have since merged. Despite its rapid growth, widespread use of eRx is not yet a reality, with approximately $26 \%$ of office-based United States (US) physicians using eRx and only $30 \%$ of them taking advantage of formulary information, according to the 2009 annual SureScripts report. ${ }^{4}$

The eHealth Initiative and the Center for Improving Medication Management, both nonprofit organizations chaired by national leaders in health care, published a joint report in June 2008, which provides a basis for understanding eRx as a type of health 
information technology (HIT). ${ }^{5}$ Computerized physician order entry (CPOE), often seen in the literature in reference to hospital systems, usually includes eRx. In fact, CPOE originated in most inpatient settings primarily to manage cost and quality in the physician-pharmacy interaction.

ERx capabilities can exist within simple standalone systems or integrated within electronic health record (EHR) or electronic medical record (EMR) systems. These systems can be programmed to offer clinical and/or formulary decision support at the point of prescribing. Depending on the capabilities of the eRx system, the physician can access patients' medication histories, including drugs that have been previously prescribed by other doctors, and medication allergies. If the eRx system is imbedded within an EHR system, there is greater availability of information such as medical history, laboratory data and past hospitalizations. As of 2010, certain standalone eRx systems are starting to include problems/diagnoses and laboratory results, without attempting to be an EMR.

An additional electronic database of importance to health outcomes research is being generated through medication therapy management services (MTMS) provided by pharmacists within the practice of pharmaceutical care. ${ }^{6-8}$ MTMS documentation systems (eg, Assurance, HealthMapRx, and others) track the patient's progress toward achieving goals of therapy including the management and resolution of drug therapy problems. ${ }^{9,10}$ The Office of the National Coordinator for Health Information Technology (ONC) is reviewing a "meaningful use" petition for a certified pharmacy EHR separate and distinct from pharmacy medication dispensing systems. ${ }^{11}$ Initiatives for conducting health economics and outcomes research can be expected to benefit from the integrated use of eRx, EHR, and patient outcomes information contained in MTMS documentation systems. Along these lines of "meaningful use", eRx software should be certified by ONC-recognized and newly created IT certifying organizations such as the Certifying Commission for Health Information Technology (CCHIT). ${ }^{12}$ Standalone eRx systems have already started the CCHIT certification process in the 2009-2010 timeframe.

eRx has many benefits over traditional prescribing for prescribers, pharmacies, patients, and payers (Table 1). ${ }^{13}$ ERx eliminates the ambiguities inherent in interpreting handwritten prescriptions. ${ }^{12,14,15} \mathrm{eRx}$ has potential to add value to patient care and decrease costs, ideas supported by both private and public sectors. ${ }^{16}$ In June 2009, the American Medical Association (AMA) announced it would sponsor an innovative "Cloud Computing" platform. Most importantly, its first main clinical feature was standalone eRx. Plans to integrate other clinical functions through modular components to emulate many EMRs have already been realized.

Some pay-for-performance (PFP) programs provide bonuses to physicians who adopt eRx or $\mathrm{EMR}^{17}$ and Title XIII of the American Recovery and Reinvestment Act (ARRA) deals with encouraging physicians to use more HIT which includes incentives for eRx, mainly through Medicare and Medicaid. The federal reimbursements amount to between \$44-64,000 earned over a 5-year period starting in January 2011. In addition, the patient-centered medical/health home initiative advocates for increased payments to health teams for achieving clinical benchmarks in the patients they serve. ${ }^{18}$

But there is added value from eRx beyond monetary gains and fulfilling requirements. The use of eRx with appropriate security and selectively deidentified data allows practitioners to contribute to research, improve performance and gather insight into aspects which may become publicly reported. ERx data can be used to answer research questions about health and economic outcomes of medical care. An important step in being able to use this data source is to determine the accuracy and reliability of the information.

\section{Evaluation of eRx data}

Eguale et al looked at the accuracy of eRx in documenting medication discontinuation or dosing changes by comparison with physician facilitated medical chart review. ${ }^{19}$ They determined that eRx was reconciled with paper records $80 \%-95 \%$ of the time and concluded that eRx is a new method for augmenting pharmacosurveillance.

Despite the accuracy of eRx in evaluating certain parameters, there are also documented risks for using eRx, which may or may not relate to the systems design. Technology may not do what it has been intended to do and may lead to unintended consequences such as patient harm or misused resources. ${ }^{20}$ There are few randomized, prospective controlled trials comparing the adverse effects of eRx systems. Typical study designs evaluate some aspect pre- and post-implementation of the eRx system. Since implementing a system usually means a major change in workflow; it may be hard to confirm if the outcome is due to the eRx system or the workflow change. Also, it is difficult to determine the unit of analysis in some studies - is it the hospital system, the single health care provider, or an isolated number of patients? Observational methods are more common and can provide real-world approximations of the usefulness of eRx systems.

One of the problems noted with eRx is that clinicians may choose the wrong medication. There are patient safety initiatives occurring to correct this error such as the inclusion of International Classification of Diseases, 9th Revision, 
Table I Benefits of electronic prescribing $(e R x)^{13}$

\begin{tabular}{|c|c|c|c|}
\hline Insurers & Prescribers & Pharmacies & Patients \\
\hline $\begin{array}{l}\text { - Improved formulary } \\
\text { compliance } \\
\text { - Reduction of medication } \\
\text { errors } \\
\text { - Identification of patient } \\
\text { nonadherence } \\
\text { - Reduction of overall } \\
\text { health care costs } \\
\text { - Provides formulary } \\
\text { support (lessens burden } \\
\text { for prior authorization/ } \\
\text { step edits for prescribers } \\
\text { to contact insurance); } \\
\text { Medicare Part D } \\
\text { formulary must be loaded } \\
\text { to eRx software } \\
\text { - Reduce health care } \\
\text { costs - encourages } \\
\text { generics, lower cost } \\
\text { options }\end{array}$ & $\begin{array}{l}\text { - Display of alternative medications with } \\
\text { economic benefit } \\
\text { - Reduction of medication errors (eg, drug- } \\
\text { drug, drug allergy, drug duplication) } \\
\text { - Reduction of work-flow interruptions (calls and } \\
\text { faxes from pharmacies, patients, and payers) } \\
\text { - Improvement of patient adherence } \\
\text { - Financial incentives for adopting eRx systems - } \\
\text { Physician reimbursement programs } \\
\text { - Can monitor patient adherence } \\
\text { - Clinical decision support software can be } \\
\text { built according to needs of practice, including } \\
\text { on-screen prompts for drug-specific dosage } \\
\text { information } \\
\text { - Creates complete medication history - } \\
\text { prescriber able to see prescriptions ordered } \\
\text { by other prescribers } \\
\text { - Practice evaluation: adherence to clinical } \\
\text { guidelines, adaptation to initiatives, } \\
\text { - Mocumenting outcomes } \\
\text { "doctor shopper" category for controlled } \\
\text { substances }\end{array}$ & $\begin{array}{l}\text { - Reduction of dispensing errors } \\
\text { related to illegible handwriting } \\
\text { drugs look-alike/sound alike } \\
\text { - Reduction of work-flow } \\
\text { interruptions (calls to } \\
\text { prescribers, patients, payers) } \\
\text { - Enhanced time for patient } \\
\text { counseling } \\
\text { - Can monitor patient } \\
\text { adherence } \\
\text { - Eliminates "falsified" written } \\
\text { prescriptions } \\
\text { - May reduce fraud and abuse } \\
\text { - Streamlines and reduces faxes } \\
\text { (duplicates, missing) sent by } \\
\text { pharmacy to prescriber for } \\
\text { refills, expedites refills }\end{array}$ & $\begin{array}{l}\text { - Patient convenience: } \\
\text { Patient may pick } \\
\text { up prescription } \\
\text { from pharmacy } \\
\text { without dropping off } \\
\text { prescription } \\
\text { - Reduction of medication } \\
\text { errors } \\
\text { - Reduce health care } \\
\text { costs - encourages } \\
\text { generics, lower cost } \\
\text { options }\end{array}$ \\
\hline
\end{tabular}

Clinical Modification (ICD-9-CM) codes on electronic prescriptions, mandatory patient counseling at the time of dispensing a new prescription, and the use of MTMS in patient-centered medical/health home designed to help patients achieve goals of therapy.

\section{Value of eRx data in outcomes studies}

The use of administrative claims databases is common in health outcomes research and quality of care assessments. ${ }^{21}$ Medical claims data contain ICD-9-CM codes to identify diagnoses whereas pharmacy claims provide information about prescription drug usage. Although claims are intended for billing purposes, researchers have been able to examine them from a population standpoint to evaluate care, gather statistical data, and look at possible interventions more efficiently than performing traditional chart reviews. Even though claims data in research can provide a great deal of information on diagnoses, procedures, and medication use, this type of data has also been criticized for capturing limited information which may not fully reflect the patient's condition. $^{22}$

The use of eRx data either from standalone systems or within EMR systems provides opportunities beyond claims data. For example, pharmacy claims data has been frequently used to evaluate persistence or adherence with medication therapy. The use of claims data can determine the length of time a patient possessed a specific medication. However, it fails to differentiate whether non persistence is prescriber or patient initiated. In addition, pharmacy claims data fail to identify those patients who have been prescribed therapy, but never filled their prescriptions (ie, first-fill failure). Due to the fact that few non prescription medications are covered by insurers, pharmacy claims data are only sparsely populated with over-the-counter drug and herbal medicine data. Conducting research with eRx data provides an efficient way to determine whether the patient did not obtain the prescribed or intended medication, sometimes referred to as first-fill failure. If a prescriber e-prescribes hydrochlorothiazide (HCTZ) for her patient, this would allow for the capture of the electronically prescribed HCTZ. A matching pharmacy claim for this patient for HCTZ would confirm that the patient obtained the medication. However, if the patient never picked up the prescription, there would be no matching pharmacy claim. The use of eRx data would identify that this patient failed to pick up the intended medication. In previous research studies where only pharmacy claims data were examined, this patient would not have been identified. Not only was this research question previously unanswerable in claims data, but it required time-consuming 
and very expensive manual chart-review where such data was sometimes difficult to locate.

Even though eRx systems were not originally developed for research, investigators have conducted studies using eRx information to understand medication adherence, compare utilization and effectiveness of therapies, evaluate the effects on medication errors, and describe the impact on physician prescribing and clinical outcomes (Table 2).

Within a practice or health system, data from eRx can be used to document quality care and to evaluate the impact of clinical initiatives on patient care outcomes. The pointof-care feedback that eRx systems can offer the practitioner impacts appropriateness of prescribing, compliance to formulary, and medication adherence. This provides an electronic dataset for studying changes in outcomes based on various types of clinical decision support (CDS).

Published studies which have used eRx data within outcomes research can be found in Table $3 .{ }^{15,19,23-44}$ The research addresses evidence-based medicine and guidelines, medication adherence, comparative effectiveness, economic evaluations, and medication errors. These studies provide a basis for examining the value of eRx to the practitioner for clinical purposes and as a component of the practitioner's contribution to an emerging body of research around real world drug utilization and surveillance. Study highlights are presented to show the practitioner the plethora of information that can be collected and studied using eRx data (Table 3).

Table 2 Opportunities for using electronic prescribing in outcomes research

- Pharmacosurveillance/adverse drug events

- Public health (surveillance/syndromic surveillance)

- Evidence-based medicine (clinical practice guidelines)

- Pharmacoepidemiology

- Joint Commission on Accreditation of Healthcare Organizations (JCAHO)

- Pay-for-performance programs

- Comparative effectiveness research

- Medication errors

- Drug interactions

- Evaluation of clinical decision support:

- Allergy warnings

- Contraindicated drugs (relative or absolute)

- Medication adherence

- Quality improvement initiatives

- Formulary compliance

- Pharmacoeconomics

- Added tools for research in fraud and abuse, particularly in controlled substances [when approved by the Drug Enforcement Administration]

\section{Future directions}

Studies that focus on the quality, efficiency and cost of care are important to clinicians, institutions, and the entire US health care system. Several factors will impact the future use of eRx data in outcomes research.

\section{Infrastructure development/support}

Large amounts of federal funds have been allocated to boost the use of health care technology, including grants for outcomes research studies. Under the Health Information Technology for Economic and Clinical Health (HITECH) Act, as part of the $\$ 19.2$ billion program promoting the adoption and use of EHRs, the government is providing over $\$ 300$ million to regional HIT efforts to create the infrastructure necessary to promote electronic exchange and the use of health information.

One area of concern among experts in the future of health outcomes and economics evaluation is that the Health Insurance Portability and Accountability Act (HIPAA) hinders important medical research studies. ${ }^{45}$ The management and use of eRx data offers both new solutions to privacy as well as new potentially problematic areas. While prescriber level data aimed at marketing is not an appropriate use, quality improvement and research initiatives using aggregated $\mathrm{eRx}$ data are. Many clinicians require their patients to sign waivers to allow access to their medication information for deidentified analyses. The use of aggregated and deidentified $\mathrm{eRx}$ data as a secondary data source can be classified by institutional review boards (IRBs) as having a low level of risk to subjects falling within the exempt review category of research. ${ }^{46}$ The use of this data involves no more than a minimal risk defined as, "the probability and magnitude of harm or discomfort anticipated in the research are not greater in and of themselves than those ordinarily encountered in daily life or during the performance of routine physical or psychological examinations of tests." Many IRBs allow for a waiver of patient consent.

Additionally, eRx and EMR systems can actually be a way for health care professionals to comply with HIPAA and decrease the amount of paperwork. In Europe, the United Kingdom, Denmark, and The Netherlands, EMR systems can perform full audit trails for access, and patients are entitled to know who has looked at their information and what information each person had viewed. Patients are ultimately given the choice to opt in, opt in with restrictions, or opt out. ${ }^{47}$ If patients have access to their eRx and EHR in the US, they can be given this choice as well. 
A committee from the Institute of Medicine (IOM) calls on Congress to authorize a totally different approach to safeguarding personal health data in research regardless of who supports or performs the research. Implementing recommendations of the IOM can be expected to facilitate scientific discovery and medical innovation necessary to enhance the quality of the public's health.

Many if not all the federal subsidies included under the ARRA and HITECH laws to assist in the purchase or reimbursement for clinical information technology targeted to physicians, hospitals, and health care providers will be contingent on the demonstration of "meaningful use" as defined by the ONC under The US Department of Health and Human Services. This specification requires that the applications must demonstrate not only improved outcomes, but lowered costs or avoidance of substantial rises in costs. The most commonly cited example of "meaningful use" in the eyes of the federal regulators as well as many think tanks is eRx. ${ }^{48}$

Research utilizing eRx data may be much simpler as systems can talk to each other. Many vendors are already working on system certification and data interoperability standards that support government reporting as well as privacy and security requirements. The purpose is to create software that uses EHR data within the context of clinician's workflow to simplify the use of data for secondary uses, thereby reducing the need for re-entering data.

Increased research power is possible with $\mathrm{e} \mathrm{R}$ because it allows for aggregation of data from different sources. Large patient registries for evaluating patient outcomes will be created, such as the Distributed Ambulatory Research in Therapeutics Network (DARTNet), a network of some 500 clinicians using EMR designed to compare effectiveness of prescription medications and medical devices. ${ }^{49}$ The DARTNet research team can query the database to obtain information about care and outcomes for hundreds of thousands of patients. In addition, the Agency for Healthcare Research and Quality has already published a user guide providing key information on developing, operating and evaluating patient registries, electronically available at www.ahrq.gov. ${ }^{50}$ With increased pervasive use of eRx by hospitals, institutions, and physician offices, more opportunities for outcomes research that allow real-world evaluations of care emerge. As each patient's record is added to an ever growing database of evidence, this aggregation of information is extremely powerful for answering questions that could not be answered previously.

\section{Pharmacoeconomic research}

The considerable recent emphasis from all stakeholders in health care, especially in light of the federal government's attempts to reform the system, point to importance of cost efficacy in future research outcomes. The addition of eRx clinical data to the research outcomes community makes studies of both new and older drugs that focus on reduced costs much easier and in fact compelling. For example, a new drug that is shown to be noninferior to an older drug, but demonstrates significantly less hospitalizations, adverse drug events (ADEs), and/or less expensive testing to monitor potential ADEs would have a major appeal. Such drugs have already been introduced to the market with those characteristics in mind when the applications for approval were submitted to the US Food and Drug Administration (FDA).

\section{Population health management}

Randomized controlled clinical trials (RCTs) are the basis for new therapies to be evaluated for approval by the FDA (safety and efficacy) as well as serving as the groundwork to make evidence-based treatment decisions (comparative effectiveness). In order to more fully assess drug safety, we rely on epidemiology or post-marketing trials to provide additional insight. Regulatory agencies such as the FDA and the Drug Enforcement Administration can take advantage of the data found in eRx systems for pharmacosurveillance purposes. Current pharmacosurveillance methods are retrospective and do not provide timely information on drug safety and effectiveness. Through eRx, real-time information can improve medication error or drug adverse event reporting if an automated surveillance system is set up. Regulatory agencies will no longer need to rely only on clinician or institutional directed reporting.

Research based on real-world data from eRx can provide supplemental evidence to RCT in population health management. While RCTs can address differences in drug efficacy in a controlled environment, there is often little incentive for pharmaceutical manufacturers to conduct RCTs with active comparators. There is a lack of literature on the relative effectiveness of therapies for a specific condition, especially agents within the same pharmacologic class. Using realworld data from eRx will enable more information on the comparative effectiveness and benefit versus risk profiles of medicines and treatments, especially for population-based decisions such as medication formularies.

Clinical decisions are often made by extrapolating evidence from clinical trials where the patient sample demographics do not match the clinician's patient. If practitioners have access 


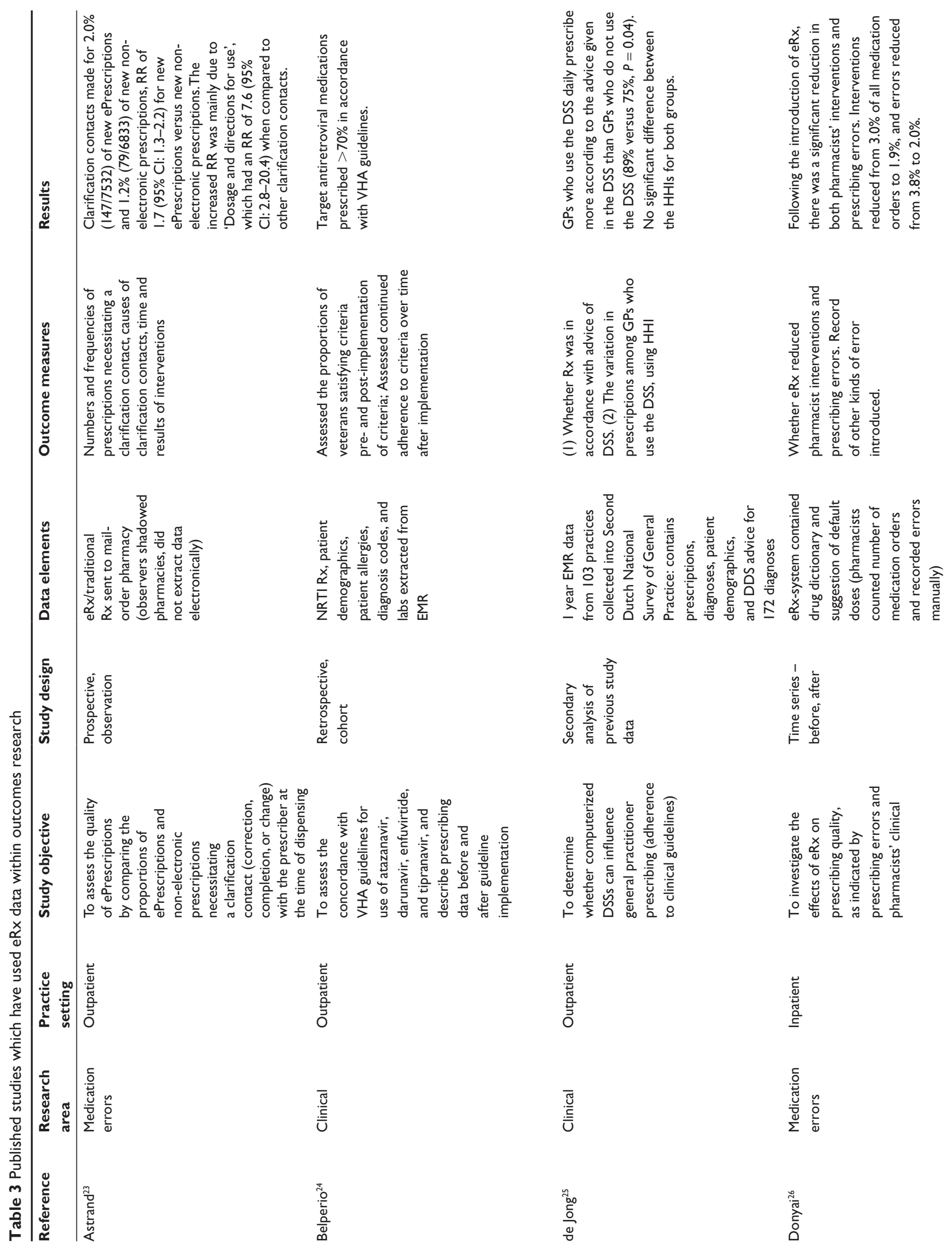



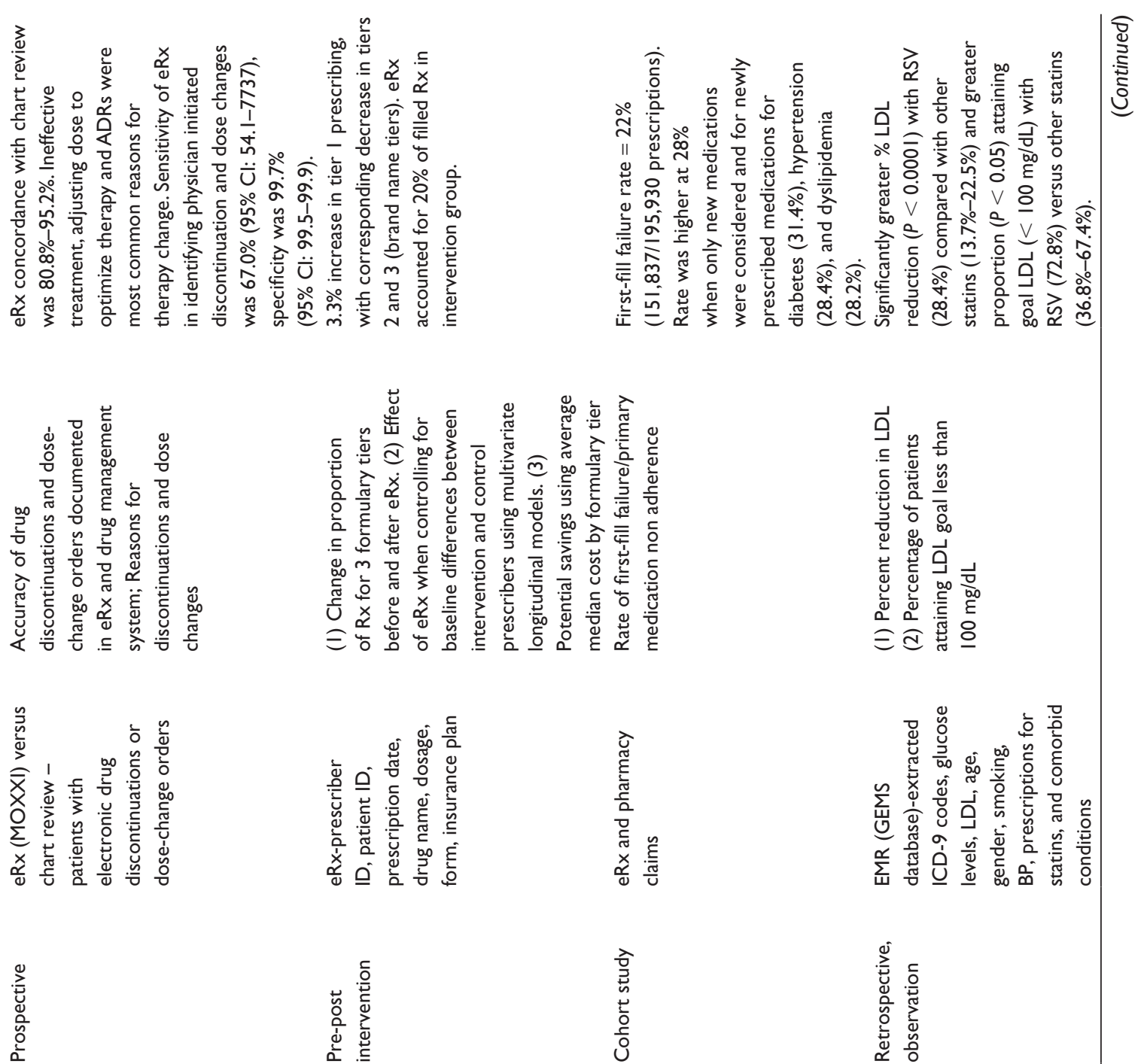

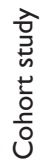
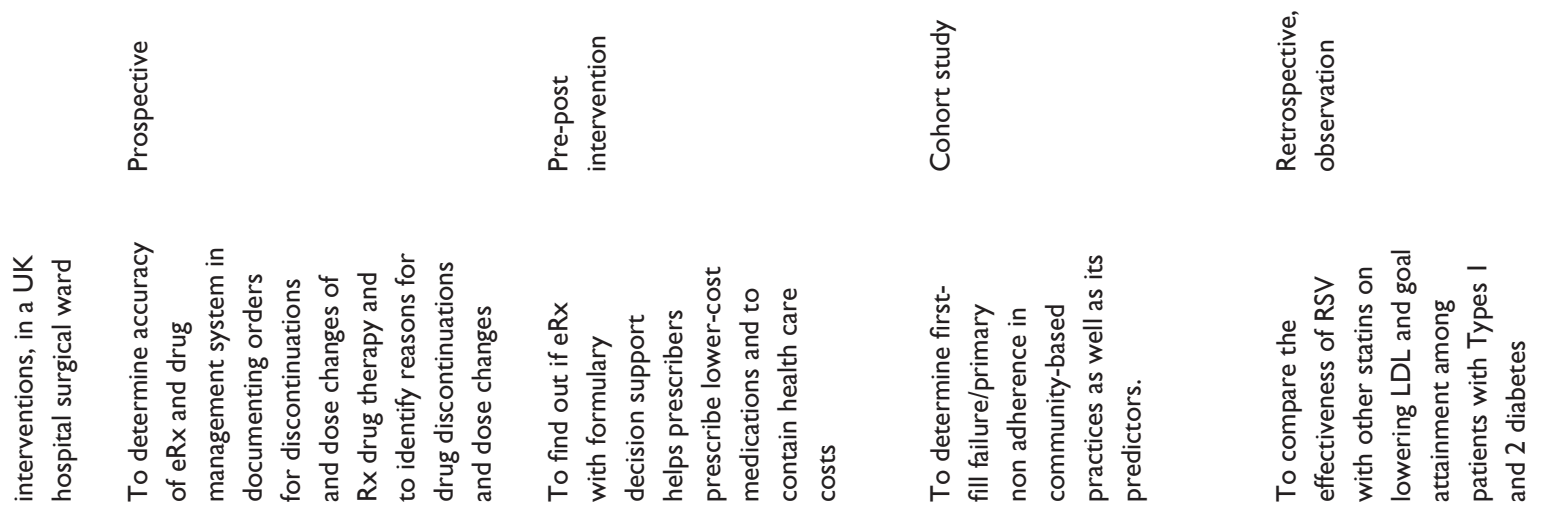

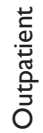

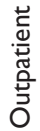

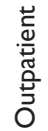

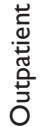

荅

"ِّ

즘

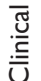

$\frac{\frac{0}{0}}{\frac{0}{30}}$

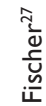

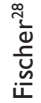

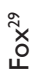




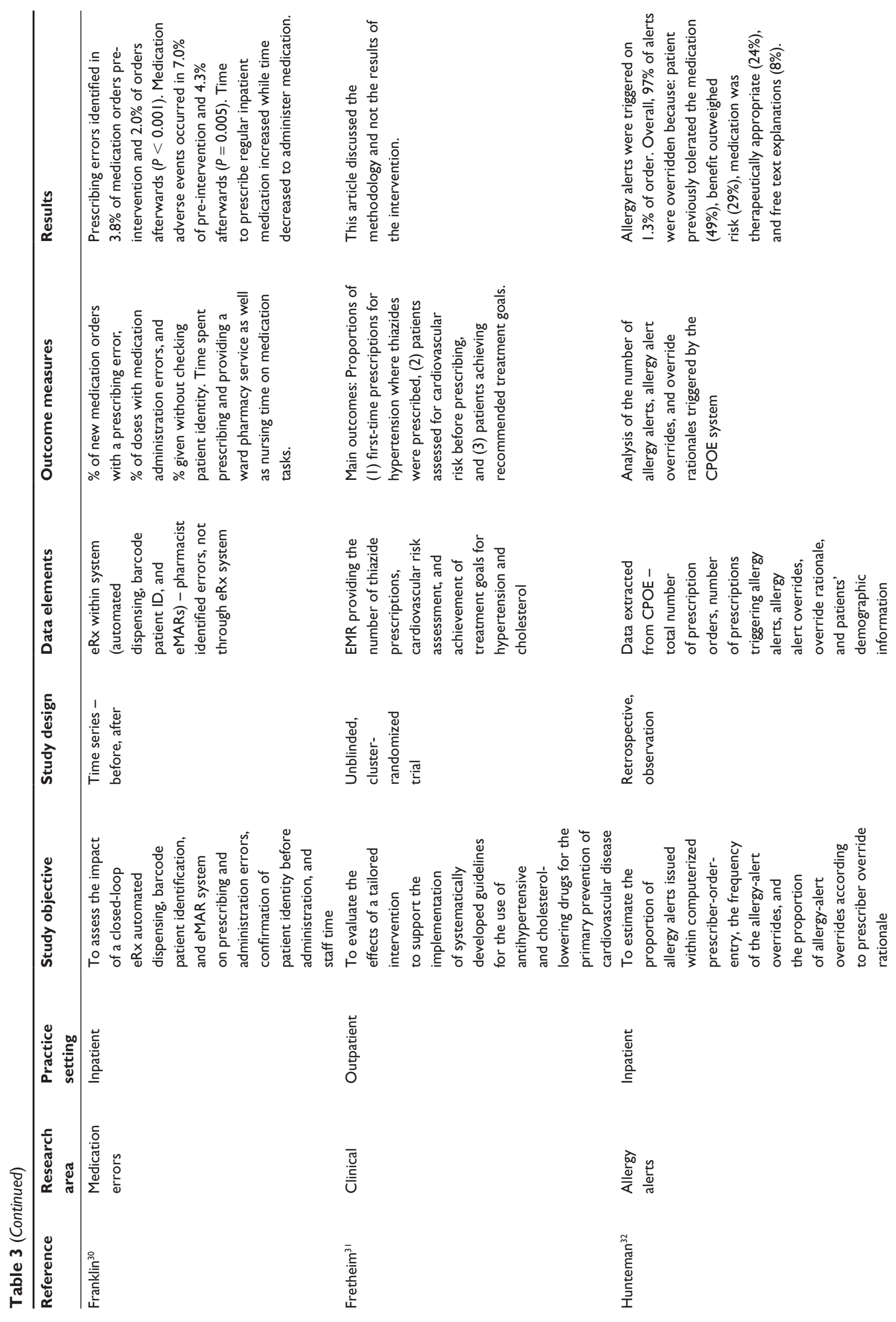




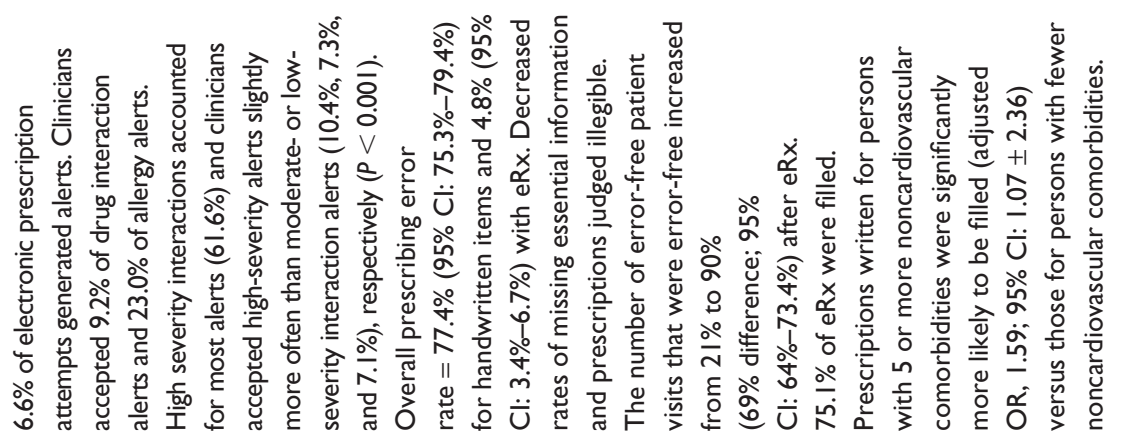

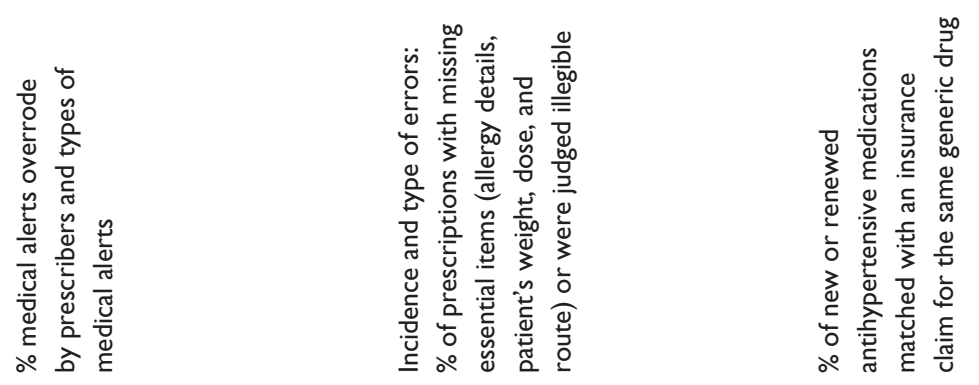

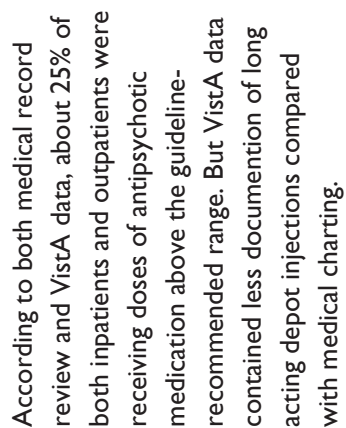

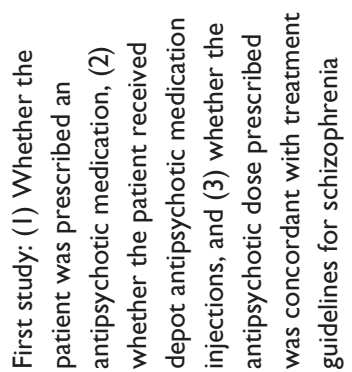

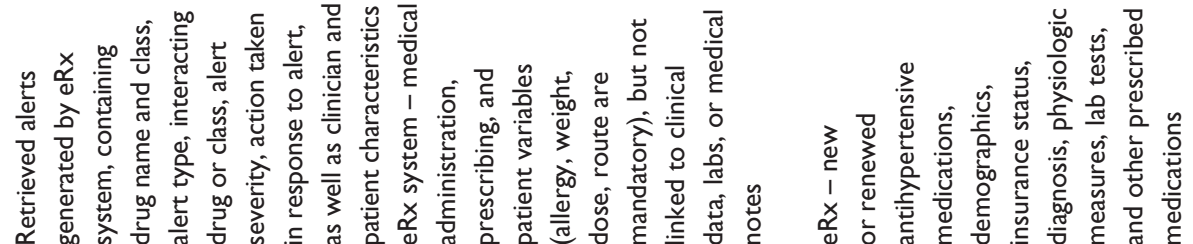

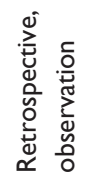

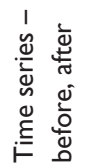

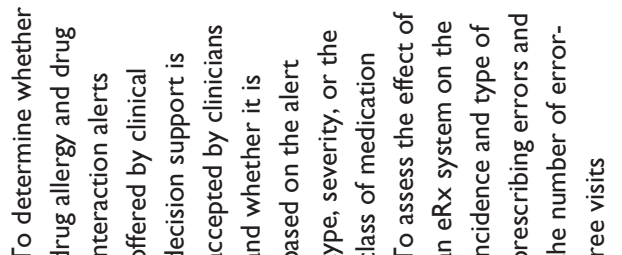

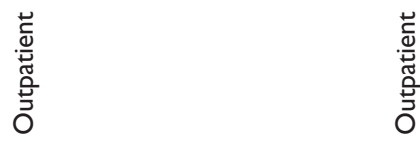

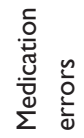

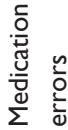

号

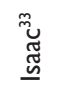

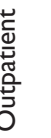

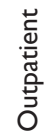

$\stackrel{\square}{0}$
$\frac{0}{\Phi}$
$\frac{0}{0}$
离

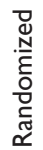

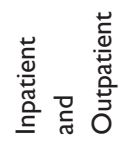

氖

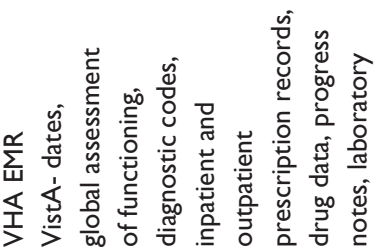

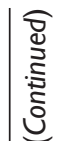




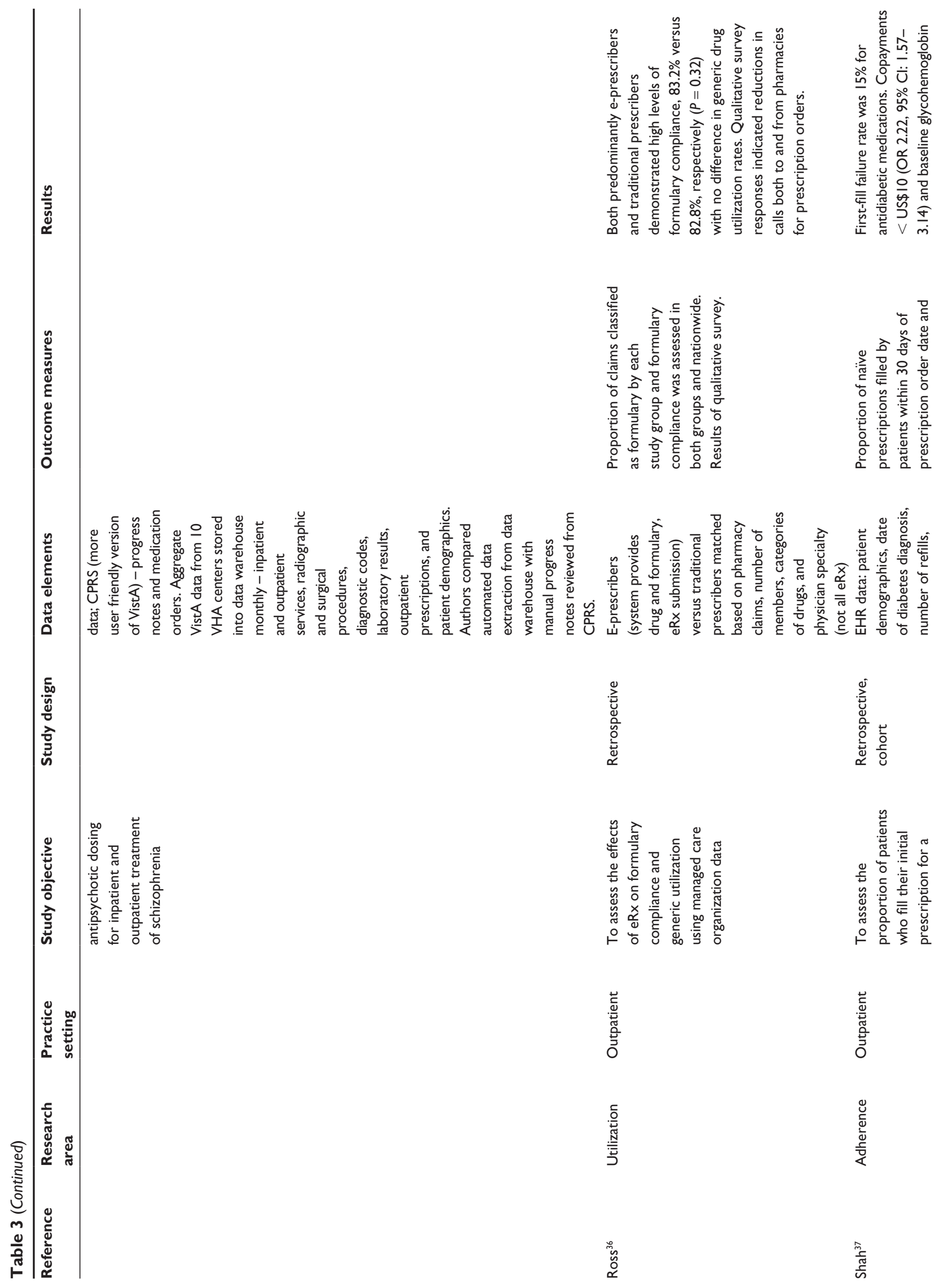



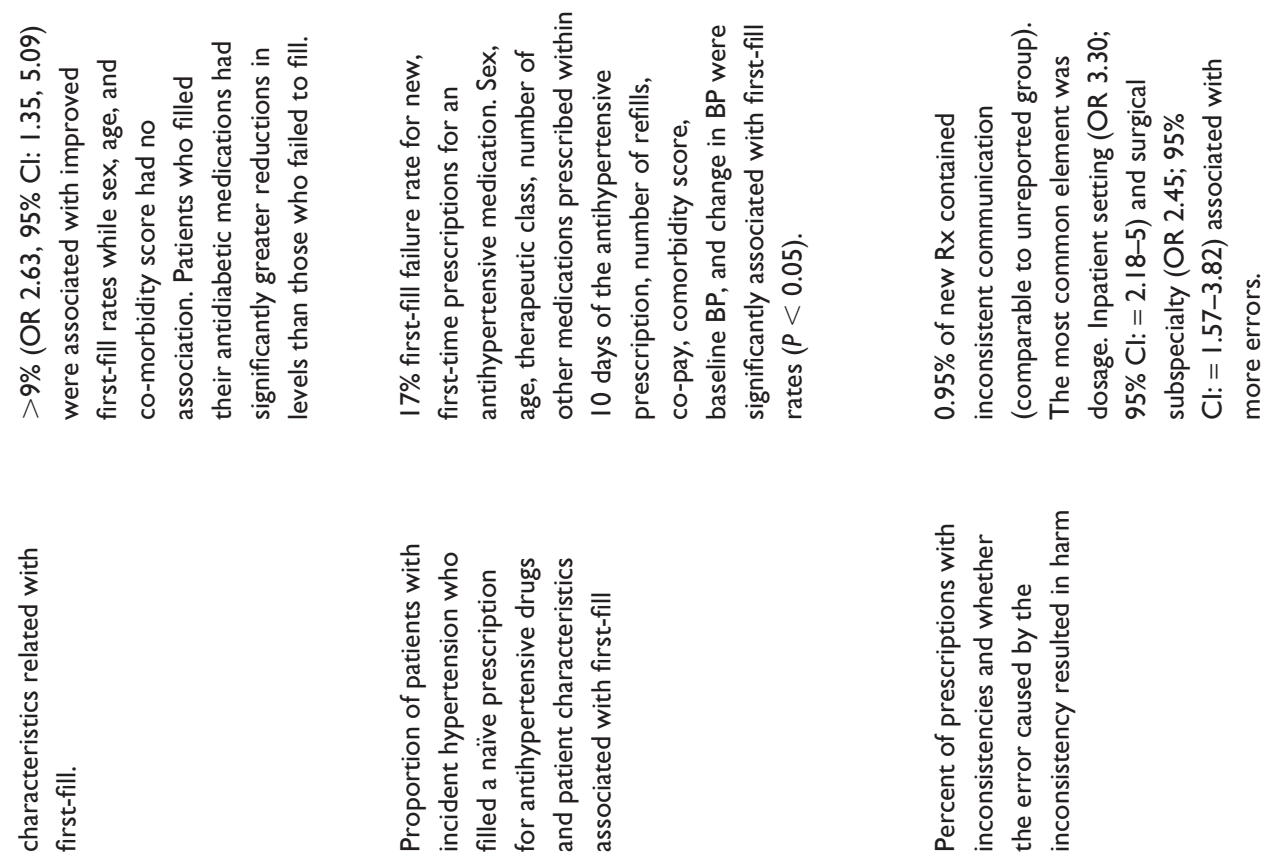

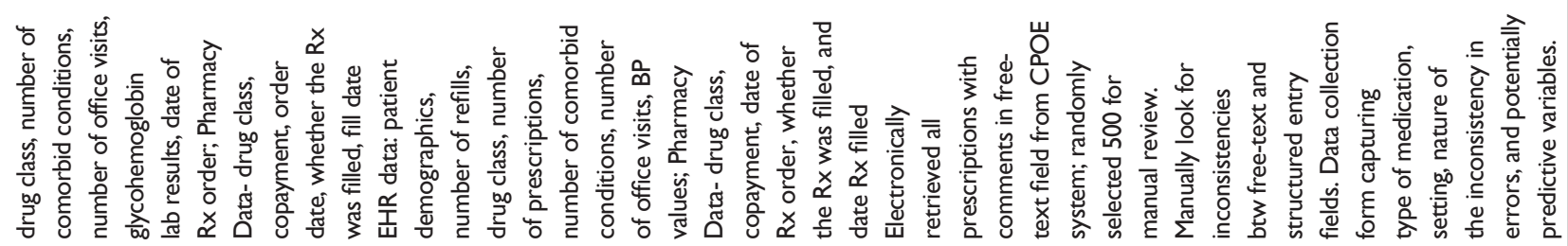

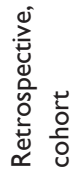

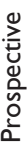
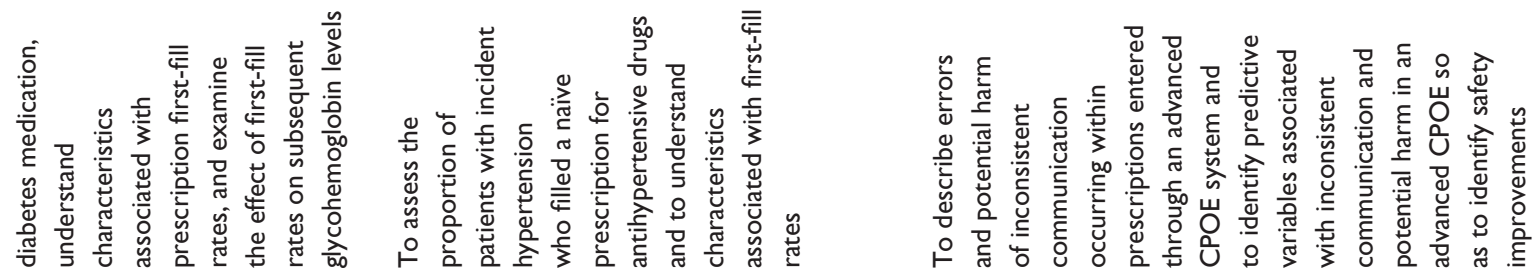

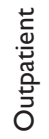

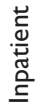

$\frac{y}{0}$
$\frac{0}{0}$
$\frac{0}{0}$
$\frac{0}{4}$

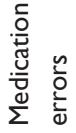

$\frac{\infty}{\frac{\pi}{n}}$

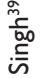




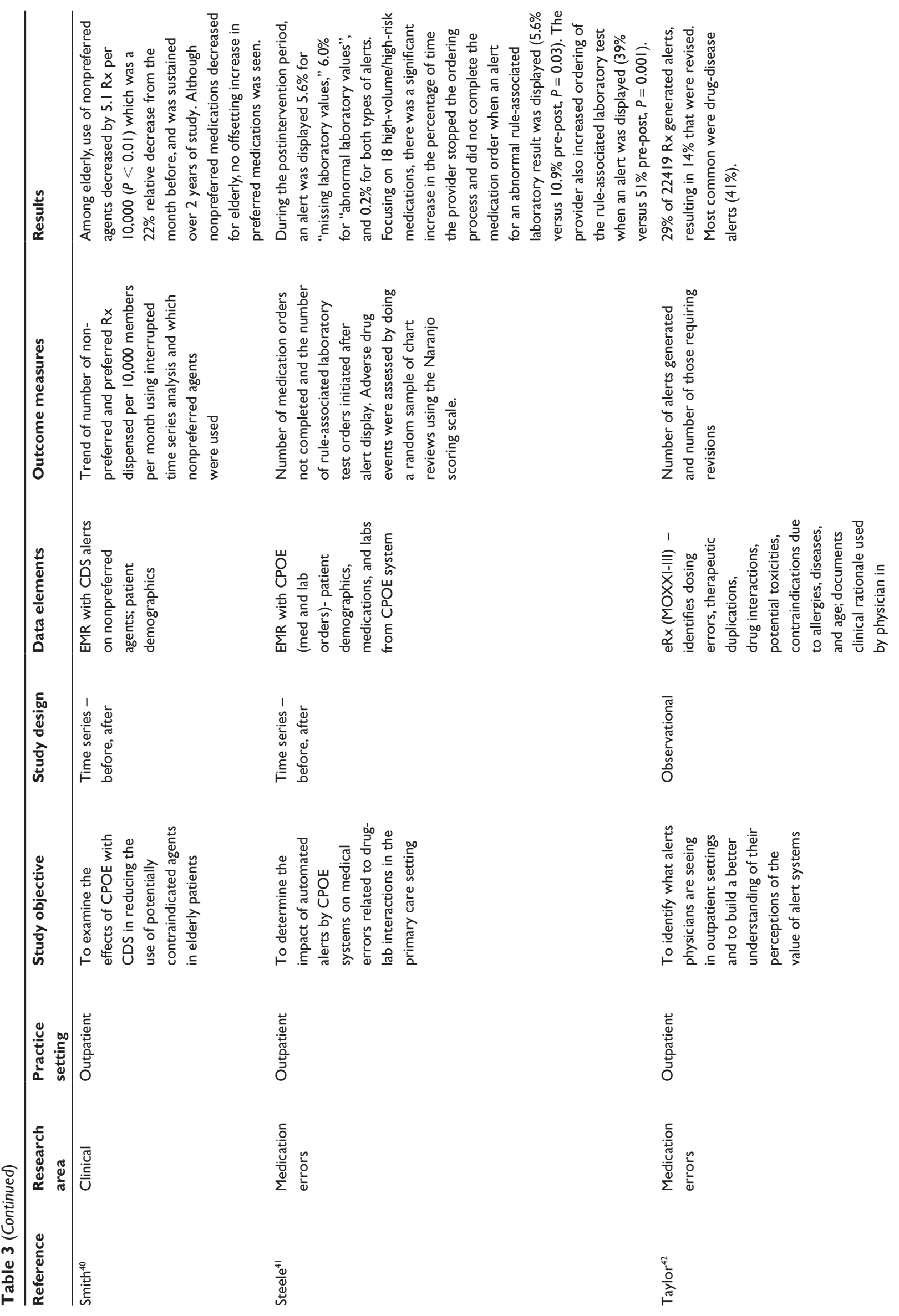




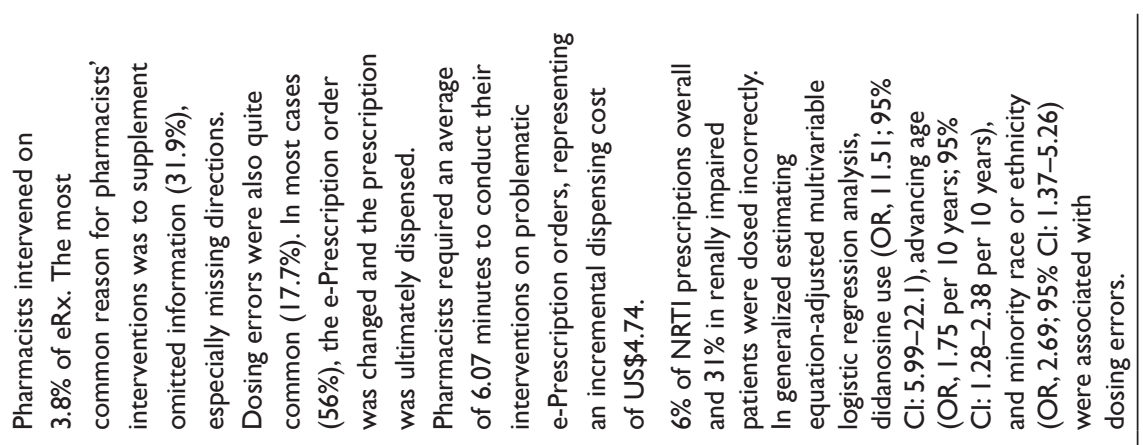

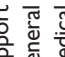

然

음 $\sum^{\frac{5}{z}} \vec{x}$.

过

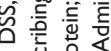

䖳

合.

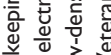

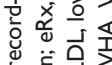
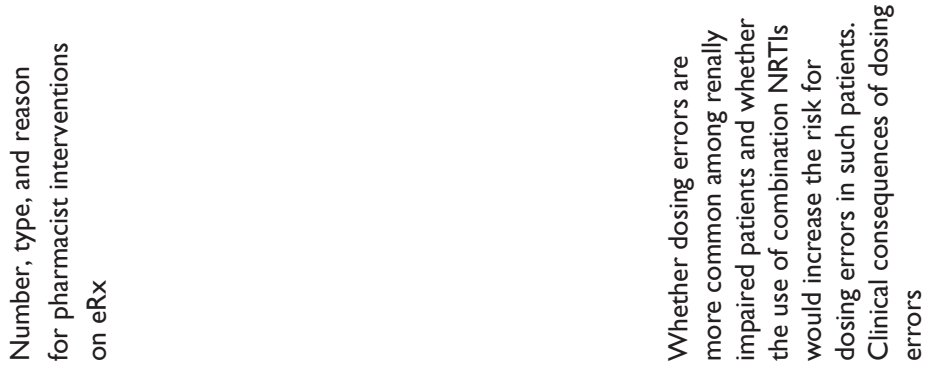

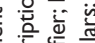

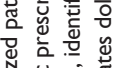

政

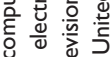

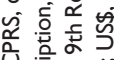

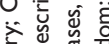

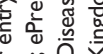

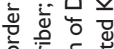

은
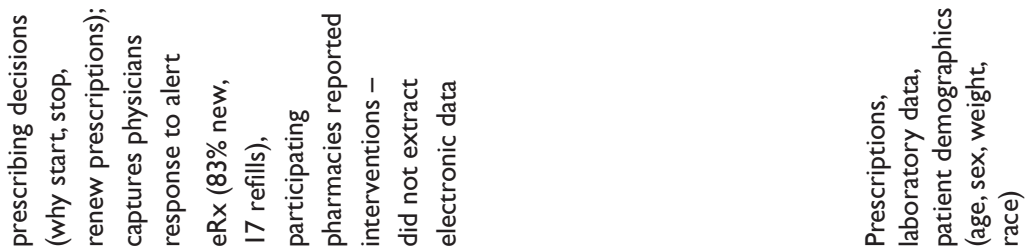

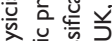

容言产

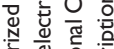

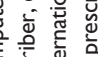

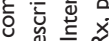

岁 के वे

U⿺辶寸

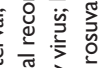

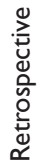

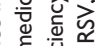

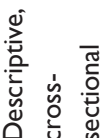

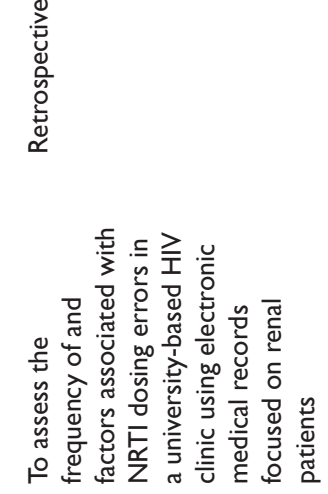

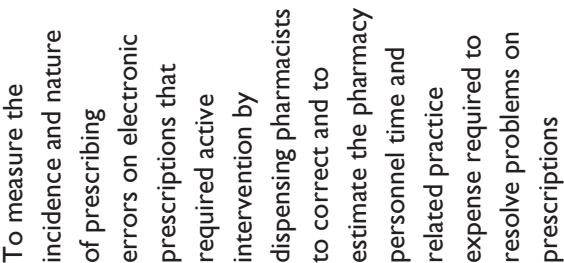

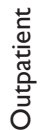

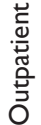

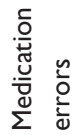

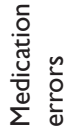

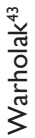

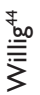

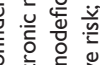

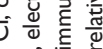

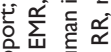

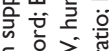

흐ㅇㅝㅛ

要

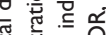

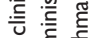

罂 究

ᄃ亦

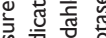

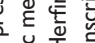

o

응 它空

के

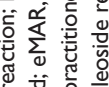

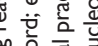

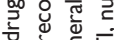

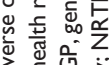

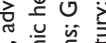

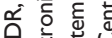

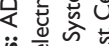

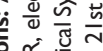

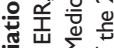

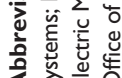


to a deidentified database of health care information, this will potentially increase the use of evidence-based medicine. For example, a query of a database on patients treated with a specific drug could identify patients with similar demographics/ clinical characteristics (eg, age, co-morbidities) to allow for evaluation of effectiveness of first-line therapies, comparative treatments, and outcomes. This information would lead to highly individualized treatment, instead of the populationbased evidence most clinicians have to go by now.

In addition, RCTs are more costly to conduct than other evaluation methodologies. Observational data from eRx and EMR, although not an alternative, can be a possible addition for testing drug efficacy in the future. Authors of a University of Pennsylvania study developed methodology to analyze EMR data for drug efficacy testing. ${ }^{51}$ Even though the results do not suggest that studies using realworld electronic data can replace RCTs due to confounding, their study is the first of its kind and will encourage further research in this area.

With eRx data, adherence to first-fill treatments will be able to be studied. ${ }^{28,37,38}$ A recently published and large study that evaluated data from a community-based $\mathrm{eRx}$ initiative included 75,589 patients treated by 1,217 prescribers. ${ }^{28}$ The authors matched e-Prescriptions with pharmacy claims and found the first-fill failure rate for all e-Prescriptions was $22 \%$. For newly prescribed common chronic conditions such as hypertension, dyslipidemia, and diabetes, first-fill failure rates were even higher and ranged from $28 \%-31 \%$. Understanding population first-fill rates will provide opportunities (via the same HIT) to notify, survey, and analyze these first-fill failures which can then provide insight into MTMS interventions.

\section{Personalized/point of care research}

Eventually, eRx systems will be adopted at the point-of-care and can even be accessible to patients. Health care providers can use practice-based research to assess effectiveness of specific drug therapies in a "local population." Connected practice-based research networks can also address regional population management research. ERx and EMR systems with CDS can provide real-world analysis of current evidence-based guidelines, incorporating prescription information (first-fill rates, adherence, and persistence) into the analysis.

ERx systems can be designed to interface with the patient. Secure emails can be sent to patients reminding them about a prescription not picked up, upcoming appointments, and required follow-up or laboratory testing.
Between visits, patients can receive automatic notifications of preventive services, tests, or behavioral actions that are due or overdue to increase effectiveness of prescribed therapy. Patients can be given access to their own medication chart for medication reconciliation. In essence, eRx systems can be a centralized care management system for patients to coordinate their own care and help address requirements for MTMS. Highly sophisticated eRx systems can provide data resources with which to study the effectiveness of such MTMS programs.

It is unclear what the future holds; but one thing is certain - because prescription information is a vital part of the health care record, most if not all EMR systems will have eRx capabilities. Both patients and associated providers will have access to portable electronic versions of patient health care records. This plethora of information can be used by the regulatory officials to determine benefits and evaluate treatments, by physicians to evaluate and coordinate care, and by researchers to answer health care related questions. Certainly, research can satisfy some of the requirements for meaningful use prescribed by the government as criterion for subsidizing or funding the purchase of HIT.

Studies can evaluate evidence-based medicine using eRx alone and in combination with other data sources. These studies can provide additional information in support of evidence-based guidelines, and this application of eRx data allows research to cross the spectrum from RCTs to realworld outcome studies based in practices.

\section{Conclusion}

Although eRx is a relatively new data source, especially in community settings, it provides promise for practitioners to contribute to outcomes research, improve performance, and gather insight into publicly reported parameters. Clinical quality improvement and patient safety considerations will now be able to more easily tie into cost and comparative effectiveness research data offering tremendous opportunities. Every step of the eRx process can be tracked electronically and pooled into a centralized data source, enabling researchers to query for relevant data much more quickly, easily, and at a lower cost. It will no longer be a question of where to get the information, but asking the right questions in order to find the answers.

\section{Acknowledgment}

The authors thank Shan Xing for her writing and editorial assistance. 


\section{Support}

This research was supported by Novartis Pharmaceuticals Corporation, East Hanover, NJ, USA.

\section{Disclosure/Conflict of interest}

Catherine Cooke has received honoraria for speaking, and holds stock from Pfizer, Inc., has consulted for AstraZeneca, Lilly, and Novartis and has received research grants from Amylin, Pfizer, Novo, BMS, and Novartis. Brian Isetts has consulted for Novartis, General Motors, Chrysler, Ford, and the United Auto Workers through the Minnesota Policy Group, LLC, has provided expert pharmacologic review services for various legal proceedings, has received grants from NIH National Library of Medicine, has a pending grant submitted to the Hexal Foundation of Germany, has served on American Pharmacists Association work groups and committees, Pharmacist Services Technical Advisory Coalition and Pharmacy Quality Alliance - Research Coordinating Council, and has received honoraria from the American Pharmacists Association as author of a textbook chapter and for presentations at pharmacy meetings. Thomas Sullivan works part time for an eRx company, DrFirst as Chief Strategic Officer. Daniel Belletti and Maren Fustgaard are employees of Novartis Pharmaceuticals Corporation.

\section{References}

1. Centers for Medicare and Medicaid Services (CMS), HHS. Medicare program; standards for e-prescribing under Medicare Part D and identification of backward compatible version of adopted standard for e-prescribing and the Medicare prescription drug program (version 8.1). Final rule. Fed Regist. 2008;73:18917-18942.

2. eHealth Initiative and The Center for Improving Medication Management. A Clinician's Guide to Electronic Prescribing. White Paper from the eHealth Initiative and The Center for Improving Medication Management, 2008. Available from: http://www.ehealthinitiative.org/sites/ default/files/e-Prescribing_Clinicians_Guide_Final(1).pdf. Accessed Jul 23, 2010.

3. Mitchell E, Sullivan F. A descriptive feast but an evaluative famine: systematic review of published articles on primary care computing during 1980-1997. BMJ. 2001;322:279-282.

4. SureScripts. 2009 Progress Report on E-Prescribing. Available from: http://www.surescripts.com/downloads/NPR/national-progress-report. pdf. Accessed Jul 23, 2010

5. eHealth Initiative. Electronic Prescribing: Becoming Mainstream Practice. A collaborative report from The eHealth Initiative and the Center for Improving Medication Management. Available from: http:// www.ehealthinitiative.org/sites/default/files/eHI_CIMM_ePrescribing_ Report_6-10-08_FINAL(1).pdf. Accessed Jul 23, 2010.

6. Barnett MJ, Frank J, Wehring H, et al. Analysis of pharmacist-provided medication therapy management (MTM) services in community pharmacies over 7 years. J Manag Care Pharm. 2009;15:18-31.

7. Millonig MK. Mapping the route to medication therapy management documentation and billing standardization and interoperabilility within the health care system: meeting proceedings. J Am Pharm Assoc. 2009;49:372-382.
8. McMahan R. Operationalizing MTM through the use of health information technology. J Manag Care Pharm. 2008;14 Suppl 2:S18-S21.

9. Isetts BJ, Brown LM, Schondelmeyer SW, Lenarz LA. Quality assessment of a collaborative approach for decreasing drug-related morbidity and achieving therapeutic goals. Arch Intern Med. 2003;163: $1813-1820$.

10. Isetts BJ, Schondelmeyer SW, Artz MB, et al. Clinical and economic outcomes of medication therapy management services: the Minnesota experience. J Am Pharm Assoc. 2008;48:203-211.

11. American Pharmaceutical Association. Re: Draft Recommendations for the Term "Meaningful Use" of Electronic Health Records. Available from: http://www.pharmacist.com/AM/Template.cfm?Section= Home2 \&CONTENTID=20088\&TEMPLATE $=/$ CM/ContentDisplay. cfm. Accessed Jul 23, 2010.

12. Figge HL. Electronic prescribing in the ambulatory care setting. Am $J$ Health Syst Pharm. 2009;66:16-18.

13. Adler KG. E-prescribing: why the fuss? Fam Pract Manag. 2009; 16:22-27.

14. Balfour DC 3rd, Evans S, Januska J, et al. Health information technology results from a roundtable discussion. J Manag Care Pharm. 2009;15 (1 Suppl A):10-17.

15. Jani YH, Ghaleb MA, Marks SD, Cope J, Barber N, Wong IC. Electronic prescribing reduced prescribing errors in a pediatric renal outpatient clinic. J Pediatr. 2008;152:214-218.

16. Conn J. Barriers for e-Rx. High costs hamper effort: report. Mod Healthc. 2008;38:48.

17. Robinson JC, Casalino LP, Gillies RR, Rittenhouse DR, Shortell SS, Fernandes-Taylor S. Financial incentives, quality improvement programs, and the adoption of clinical information technology. Med Care. 2009;47:411-417.

18. Patient-centered Primary Care Collaborative. Integrating the Patient Centered Medical Home into a Health Reform Proposal. Available from: http://www.pcpcc.net/content/integrating-patientcentered-medical-home-a-health-reform-proposal. Accessed Jul 23, 2010.

19. Eguale T, Tamblyn R, Winslade N, Buckeridge D. Detection of adverse drug events and other treatment outcomes using an electronic prescribing system. Drug Saf. 2008;31:1005-1016.

20. Rosenbloom ST. Approaches to evaluating electronic prescribing. $J A m$ Med Inform Assoc. 2006;13:399-401.

21. Dean BB, Lam J, Natoli JL, Butler Q, Aguilar D, Nordyke RJ. Review: use of electronic medical records for health outcomes research: a literature review. Med Care Res Rev. 2009;66:611-638.

22. Weiner MG, Lyman JA, Murphy S, Weiner M. Electronic health records: high-quality electronic data for higher-quality clinical research. Inform Prim Care. 2007;15:121-127.

23. Astrand B, Montelius E, Petersson G, Ekedahl A. Assessment of ePrescription quality: an observational study at three mail-order pharmacies BMC Med Inform Decis Mak. 2009;9:8.

24. Belperio PS, Mole LA, Boothroyd DB, Backus LI. Provider prescribing of 4 antiretroviral agents after implementation of drug use guidelines in the Department of Veterans Affairs. J Manag Care Pharm. 2009; 15:323-334.

25. de Jong JD, Groenewegen PP, Spreeuwenberg P, Westert GP, de Bakker DH. Do decision support systems influence variation in prescription? BMC Health Serv Res. 2009;9:20.

26. Donyai P, O’Grady K, Jacklin A, Barber N, Franklin BD. The effects of electronic prescribing on the quality of prescribing. Br J Clin Pharmacol. 2008;65:230-237.

27. Fischer MA, Vogeli C, Stedman M, Ferris T, Brookhart MA, Weissman JS. Effect of electronic prescribing with formulary decision support on medication use and cost. Arch Intern Med. 2008;168: 2433-2439.

28. Fischer MA, Stedman MR, Lii J, et al. Primary medication nonadherence: analysis of 195,930 electronic prescriptions. J Gen Intern Med. 2010;25(4):284-290. 
29. Fox KM, Gandhi SK, Ohsfeldt RL, Blasetto JW, Bays HE. Effectiveness of rosuvastatin in low-density lipoprotein cholesterol lowering and National Cholesterol Education Program Adult Treatment Panel guideline III LDL-C goal attainment compared to other statins among diabetes mellitus patients: a retrospective study using an electronic medical records dataset in the United States. Curr Med Res Opin. 2007;23: 2125-2133.

30. Franklin BD, O'Grady K, Donyai P, Jacklin A, Barber N. The impact of a closed-loop electronic prescribing and administration system on prescribing errors, administration errors and staff time: a before-and-after study. Qual Saf Health Care. 2007 Aug;16: 279-284.

31. Fretheim A, Oxman AD, Treweek S, Bjørndal A. Rational Prescribing in Primary Care (RaPP-trial). A randomised trial of a tailored intervention to improve prescribing of antihypertensive and cholesterol-lowering drugs in general practice [ISRCTN48751230]. BMC Health Serv Res. 2003;3:5.

32. Hunteman L, Ward L, Read D, Jolly M, Heckman M. Analysis of allergy alerts within a computerized prescriber-order-entry system. Am J Health Syst Pharm. 2009;66:373-377.

33. Isaac T, Weissman JS, Davis RB, Massagli, et al. Overrides of medication alerts in ambulatory care. Arch Intern Med. 2009;169:305-311.

34. Lagu T, Weiner MG, Eachus S, Tang SS, Schwartz JS, Turner BJ. Effect of patient comorbidities on filling of antihypertensive prescriptions. Am J Manag Care. 2009;15:24-30.

35. Owen RR, Thrush CR, Cannon D, et al. Use of electronic medical record data for quality improvement in schizophrenia treatment. $J \mathrm{Am} \mathrm{Med}$ Inform Assoc. 2004;11:351-357.

36. Ross SM, Papshev D, Murphy EL, Sternberg DJ, Taylor J, Barg R. Effects of electronic prescribing on formulary compliance and generic drug utilization in the ambulatory care setting: a retrospective analysis of administrative claims data. J Manag Care Pharm. 2005;11:410-415.

37. Shah NR, Hirsch AG, Zacker C, Taylor S, Wood GC, Stewart WF. Factors associated with first-fill adherence rates for diabetic medications: a cohort study. J Gen Intern Med. 2009;24:233-237.

38. Shah NR, Hirsch AG, Zacker C, et al. Predictors of first-fill adherence for patients with hypertension. Am J Hypertens. 2009;22:392-396.

39. Singh H, Mani S, Espadas D, Petersen N, Franklin V, Petersen LA. Prescription errors and outcomes related to inconsistent information transmitted through computerized order entry: a prospective study. Arch Intern Med. 2009;169;982-989.
40. Smith DH, Perrin N, Feldstein A, et al. The impact of prescribing safety alerts for elderly persons in an electronic medical record: an interrupted time series evaluation. Arch Intern Med. 2006;166:1098-1104.

41. Steele AW, Eisert S, Witter J, et al. The effect of automated alerts on provider ordering behavior in an outpatient setting. PLoS Med. 2005;2:e255.

42. Taylor LK, Kawasumi Y, Bartlett G, Tamblyn R. Inappropriate prescribing practices: the challenge and opportunity for patient safety. Healthc Q. 2005;8 Spec No:81-85.

43. Warholak TL, Rupp MT. Analysis of community chain pharmacists' interventions on electronic prescriptions. J Am Pharm Assoc. 2009;49:59-64.

44. Willig JH, Westfall AO, Allison J, et al. Nucleoside reverse-transcriptase inhibitor dosing errors in an outpatient HIV clinic in the electronic medical record era. Clin Infect Dis. 2007;45:658-661.

45. Malin B, Karp D, Scheuermann RH. Technical and policy approaches to balancing patient privacy and data sharing in clinical and translational research. J Investig Med. 2010;58:11-18.

46. Code of Federal Regulations. Title 45: Public Welfare. Department of Health and Human Services. Protection of Human Subjects. Available from: http://www.hhs.gov/ohrp/documents/OHRPRegulations.pdf. Accessed Jul 23, 2010.

47. Deutsch H, Turisco F. Accomplishing EHR/HIE (EHEALTH): Lessons from Europe. CSC. Available from: http:/www.federalnewsradio.com/ pdfs/CSC_Accomplishing_EHR_HIE_eHealth_Lessons_from_Europe. pdf. Accessed Jul 23, 2010.

48. Markle Foundation - Connecting for Health. Available from: http:// www.connectingforhealth.org/. Accessed Jul 23, 2010.

49. Pace WD, Cifuentes M, Valuck RJ, Staton EW, Brandt EC, West DR. An electronic practice-based network for observational comparative effectiveness research. Ann Intern Med. 2009;151: $338-340$.

50. User's Guide to Registries Evaluating Patient Outcomes: Summary. Agency for Health Care Quality and Research. Available from: http://www.effectivehealthcare.ahrq.gov/ehc/products/21/12/ PatOutExecSumm.pdf. Accessed Jul 23, 2010.

51. Tannen RL, Weiner MG, Xie D. Use of primary care electronic medical record database in drug efficacy research on cardiovascular outcomes: comparison of database and randomised controlled trial findings. BMJ. 2009;338:b81.
Patient Related Outcome Measures

\section{Publish your work in this journal}

Patient Related Outcome Measures is an international, peer-reviewed, open access journal focusing on treatment outcomes specifically relevant to patients. All aspects of patient care are addressed within the journal and practitioners from all disciplines are invited to submit their work as well as healthcare researchers and patient support groups. Areas covered will

Submit your manuscript here: http://www.dovepress.com/patient-related-outcome-measures-journal

\section{Dovepress}

include: Quality of life scores; Patient satisfaction audits; Treatment outcomes that focus on the patient; Research into improving patient outcomes; Hypotheses of interventions to improve outcomes; Short communications that illustrate improved outcomes; Case reports or series that show an improved patient experience; Patient journey descriptions or research. 